\title{
Control integrado de la mosca Stomoxys calcitrans en el cultivo de palma de aceite (Elaeis guineensis Jacq)
}

Integrated control of the Stomoxys calcitrans fly in the oil palm cultivation

(Elaeis guineensis Jacq)

\begin{abstract}
Martínez Perilla Julio Andrés ${ }^{1}$, Calvache Guerrero Hugo ${ }^{2}$ y Mantilla González Carlos Eduardo ${ }^{3}$

${ }^{1}$ Ingeniero Agrónomo, Universidad de los Llanos; ${ }^{2}$ Ingeniero Agrónomo, MSc. CENIPALMA; $y^{3}$ Ingeniero Agrónomo, MSc PhD, Docente UNILLANOS

\section{cmantilla@unillanos.edu.co}

Recibido 05 de Junio 2013, Aceptado 15 de Julio 2013

\section{RESUMEN}

La producción masiva de raquis fresco en los cultivos de palma africana (Elaeis guineensis Jacq) han generado la oportunidad de desarrollo biológico de la mosca brava o de los establos Stomoxys calcitrans, incrementado la población de este insecto hematófago, afectando las ganaderías de la región, de Villanueva (Casanare). Para determinar la fluctuación poblacional de esta mosca sobre los montones de raquis dispuestos en campo se realizó un ensayo para lo cual se seleccionaron los lotes denominados F 15, F 16, F 17, F 18, E 20, E 21, E 22 y E 23 , teniendo en cuenta la cercanía al sitio de acopio de raquis para favorecer la presencia de mosca de los establos. La distribución de los tratamientos en los lotes se hizo en bloques completos al azar. De acuerdo a los resultados si se observó un efecto del cubrimiento del raquis con carpas hechas de lonas, sobre la población de mosca. Los tratamientos 20,25 y 30 días con carpa con y sin Spalangia $s p$. fueron los que presentaron un mayor desarrollo biológico de la mosca de los establos. El parasitismo de Spalangia sp sobre pupas de mosca de los establos, disminuyó en $16.35 \%$ la población, lo cual demuestra la importancia de las liberaciones de este parasitoide, ratificando la necesidad de mantener poblaciones establecidas en campo, para un eventual manejo de raquis con carpas de lona, como un componente dentro de la técnica del cubrimiento. 
También se observó que existe un factor de mortalidad natural de $41 \%$ de mosca de los establos en estado de pupa en campo.

Palabras clave: Mosca hematófaga, palma africana.

\begin{abstract}
The mass production of fresh rachis palm crops (Elaeis guineensis Jacq) generated the biological development opportunity fly stables (Stomoxys calcitrans), increased the population of this blood-sucking insect, affecting livestock in the region, Villanueva (Casanare). To determine the population dynamics of this fly on rachis mounds arranged in field testing was performed for which selected lots were called: F 15, F 16, F 17, F 18, E 20, E 21, E 22 and E 23, considering the proximity to the rachis collection site to promote the presence of stable fly. The distribution of the batch treatments was randomized complete block. According to the results if there was an effect of covering the spine with tents made of tarps on the fly populations. Treatments 20, 25 and 30 days without Spalangia sp. tent were those with a higher biological development of the stable fly Spalangia $s p$. parasitism of pupae stable fly, fell $16.35 \%$ of the population, demonstrating the importance of releases of this parasitoid, ratifying the need to maintain established populations in the field, for eventual management of rachis with canvas tents, as a component within the coating technique. It was also noted that there is a factor of $41 \%$ natural mortality of stable fly pupal stage in field.
\end{abstract}

Keywords: Hematophagous fly, oil palm.

\title{
INTRODUCCIÓN
}

En Colombia la investigación en palma de aceite apunta a promover la competitividad de este sector, garantizando su desarrollo sostenible y el cumplimiento de su función social. Esto se logrará mediante la búsqueda de cambios tecnológicos que mejoren la eficiencia de los factores productivos, que reduzcan los riesgos técnicos de la producción y garanticen la calidad de los productos de la palma de aceite. 
La experiencia de trabajo fue con los productores que están siendo asesorados por CENIPALMA, que se encuentran ubicados de Villanueva (Casanare), donde la principal actividad económica está sustentada por la producción agrícola y pecuaria, destacándose la de carne bovina, arroz, algodón, forestales, soja, maíz, plátano y palma de aceite. Esta última con un grado mínimo de industrialización para la extracción de aceite y derivados (León, 2003).

En el proceso de transformación primaria del fruto de palma de aceite se generan subproductos como raquis y fibra, los cuales son retornados al campo como materia orgánica, con el doble propósito de reciclar los nutrientes extraídos por el cultivo y mejorar la bioestructura del suelo mediante la proliferación de microorganismos, que se establecen alrededor de la descomposición del raquis, (Bernal, 2001). La producción masiva de raquis fresco y la oportunidad de desarrollo biológico de la mosca brava o de los establos Stomoxys calcitrans, ha incrementado la población de este insecto hematófago, afectando las ganaderías de la región (ICA, 2002).

Desde 1993 se vienen adaptando tecnologías para su manejo como la liberación masiva de parasitoides de pupas de mosca, Spalangia sp., trampas de monitoreo y control de los adultos. No obstante, durante la época de lluvia estas prácticas no son suficientes lo que hace necesario la búsqueda de alternativas de control que permitan ser aplicadas como prácticas de contingencia durante esta época. En el presente trabajo se muestran dos experimentos de manejo de la mosca de los establos, los cuales fueron analizados por separado $y$, los cuales incluyen, el efecto del cubrimiento de raquis fresco con carpas hechas de lonas de fertilizantes y un estudio preliminar del ciclo de vida de un coleóptero y su efecto depredador sobre larvas de mosca de los establos en campo.

\section{IMPORTANCIA DEL RAQUIS EN LA PALMA DE ACEITE}

En el proceso productivo de la palma de aceite quedan algunos subproductos como el raquis, siendo el contenido de nutrientes ( $\mathrm{kg} /$ tonelada): nitrógeno 7 , fósforo 0.9 potasio 22.4 , azufre 1 , calcio 2.7 , magnesio1.5 hierro 0.5 , manganeso 
0.06 , cobre; 0.014 , boro 0.025 , zinc 0.05 y sodio 0.018 . Además de su papel como fertilizante, tiene funciones muy valiosas como las de ayudar a corregir la estructura del suelo, factor determinante en el desarrollo radicular de la planta, así como las de aportar microorganismos que mejoran las propiedades fisicoquímicas y microbiológicas del suelo, como es el caso de las bacterias nitrificantes, hongos micorrizógenos y antagónicos aumentado sus cantidades en comparación con aquellos hongos fitopatógenos que limitan muchas explotaciones agrícolas, (Reyes et al., 1997).

Varios ensayos en una plantación en Puerto Wilches, Santander, se encontraron que, con la aplicación de raquis al cultivo durante tres años consecutivos, se incrementó la producción promedio en $28,58 \%$, equivalente a 6.26 toneladas de racimo de fruto fresco (RFF)/ha/año. A nivel semicomercial la respuesta de la aplicación de tusa, oscila entre 23,7 y $38,37 \%$, correspondiente a 4,77 y 7,72 toneladas de RFF/ha/año respectivamente; además con la aplicación de raquis se mejoraron las propiedades físicas del suelo incrementándose la porosidad, propiedad que se afecta con la compactación y que tiene entre otras funciones mejorar la velocidad de infiltración, mejorando el desarrollo del sistema radicular, Adicionalmente se ha observado un buen estado sanitario de las palmas, especialmente disminuyendo la severidad del añublo foliar causado por Pestalotiopsis sp y Gloesporium sp (Reyes et al., 1997).

\section{IMPORTANCIA DE LA MOSCA Stomoxys calcitrans}

La mosca Stomoxys calcitrans se ha constituido en un problema grave en los Llanos Orientales, como consecuencia de la producción a gran escala de raquis o tusa y de su utilización en el proceso productivo de la palma de aceite. Esta mosca, proveniente de establos y muladares, de hábitos hematófagos (animales) en el estado adulto, ha encontrado en la tusa, recién salida de la planta extractora, un medio muy especial para la ovoposición y desarrollo de la fase larval, dando origen a niveles altos poblacionales, que vienen afectando las ganaderías de la región (CENIPALMA, 1995). 
Las moscas que afectan el ganado son transmisoras y diseminadoras de enfermedades infecciosas siendo las más comunes: anaplasmosis, fiebre aftosa, mastitis, algunas veces carbón sintomático y bacteriano, paustellorosis, querato conjuntivitis y otras enfermedades infecciosas. Además, éstas moscas causan irritación y estrés en el animal, por consiguiente, contribuyen a disminuir su productividad (Serrano, 1996).

Se ha investigado el efecto negativo de estas moscas picadoras sobre la producción animal, puesto que se alimentan de sangre, un solo insecto puede ingerir hasta 16 miligramos de sangre por succión y en esta forma los hospederos, ósea los animales, pueden sufrir de anemia de acuerdo con el grado de infestación (Serrano, 1996).

En cuanto al efecto de Stomoxys calcitrans sobre la producción de carne se han hecho algunas evaluaciones, es así que Campbell en 1993, encontró que los animales que estaban libres de mosca tenían un promedio de peso de 90 gramos por día más alto que los animales que no habían sido tratados, en un ensayo que duró 100 días, donde la carga poblacional de estos terneros estaba en promedio de 50 moscas por animal. El efecto del control de moscas en la producción de leche, también ha sido evaluado, se ha indicado que las perdidas en la producción de leche ocasionadas por Stomoxys calcitrans pueden llegar hasta en un $20 \%$, Morgan y Bailie en 1980 encontraron que vacas tratadas para su control mejoraban la producción diaria de leche en aproximadamente $1 \mathrm{~kg}$.

Clasificación taxonómica de Stomoxys calcitrans:

Phylum: $\quad$ Artropóda

Clase: Insecta

Orden: Díptera

Suborden: Cyclorrhapha

Familia: Muscidae 
Género: $\quad$ Stomoxys

Especie: $\quad$ Stomoxys calcitrans $(\mathrm{L})$

Nombre vulgar: Mosca de los establos, mosca brava, y otros (Georgi, 1985).

Este insecto está ampliamente distribuido en todos los continentes; en América fue introducido de Europa en el siglo XVIII. Existen muchas referencias respecto a la duración de su ciclo de vida, lo cual dependerá de las condiciones climáticas; en términos generales, para las zonas palmeras de Colombia, ésta puede resumirse de la siguiente forma: huevo de 23 a 24 horas; larva de 6 a 8 días; pupa de 5 a 8 días y adulto de 13 a 18 días, para un total de 32 a 35 días de vida (CENIPALMA, 2003).

Esta mosca deriva su nombre vulgar de su cercana asociación con los animales domésticos, puede picar también a humanos, se conoce como la mosca de los establos, mosca del ganado, mosca brava o mosca, la hembra y el macho son hematófagos, succionan sangre cada 2 o 3 días, con una duración de 8 minutos y en una sola alimentación, a menudo, pinchan la piel varias veces antes de chupar sangre, siendo dolorosa su picadura, en las noches son inactivas (Camppell et al., 1993; Cumming y Cooper, 2000; Okedi, 1995; Powell, 1995).

Experimentalmente se comprobó que el azul atrae más a estos insectos que los otros colores (Díaz et al., 1997), siendo sus sitios de reposos favoritos las cercas soleadas y paredes en general, si las moscas son perturbadas tienden a regresar al sitio inicial, estos insectos en condiciones normales pueden volar varios kilómetros para buscar alimento, aumentando sus poblaciones en épocas lluviosas con temperaturas altas (Georgi, 1985). La hembra puede colocar durante su vida entre 600 a 800 huevos en excrementos de caballos y ganado, en la paja contaminada con orina y heces, césped cortado, frutas y derivados vegetales. En el agroecosistema de la palma de aceite, la hembra coloca los huevos sobre las tusas frescas y estas se constituyen en el sitio de reproducción más común de la mosca. En cada ovoposición pueden dejar grupos de 60 a 270 huevos (Okedi, 1995; Powell, 1995). 
La larva es muscidiforme, más delgada que la de la mosca doméstica, con un solo gancho bucal, de color blanco cremoso y presenta unas sétulas o microespinas ventrales, localizadas entre los segmentos abdominales 1 a 7 , cuando ha alcanzado su último instar mide entre 10 a $12 \mathrm{~mm}$ de longitud. La pupa es de tipo coarctata; color marrón oscuro a rojizo, mide de 4 a $7 \mathrm{~mm}$ de longitud (CENIPALMA, 2003).

La larva y la pupa se desarrollan entre la materia orgánica y se alimenta de las bacterias que en ella crecen, para el caso de la palma de aceite, se alimenta de bacterias que proliferan en la tusa apenas inicia su proceso de descomposición, lo cual sucede dos o tres días después de sacada de la planta extractora, iniciando su colonización (CENIPALMA, 2003). La pupa también se desarrolla entre la materia orgánica, ubicándose en los sitios más secos, principalmente entre la fibra del pedúnculo del racimo vacío (Okedi, 1995).

La mosca adulta se diferencia sustancialmente de la mosca casera porque tiene una proboscis negra o pico duro, no retráctil, que se proyecta hacia la parte inferior de la cabeza; la utiliza para atravesar la piel y succionar sangre. Además, es de color grisáceo, con cuatro franjas longitudinales negras dorsales en el tórax. El abdomen es más ancho que el de la mosca casera y tiene un "tablero de damas" en la zona dorsal, conformada por manchas oscuras, redondeadas, es de color amarillento y forma ovoide, con un abultamiento, mide aproximadamente un milímetro de longitud (CENIPALMA, 2003).

\section{CONTROL Y MANEJO DE LA MOSCA DE LOS ESTABLOS}

La constante insistencia de la comunidad y de las plantaciones de esta zona, con relación a la presencia de mosca hematófaga en los hatos, y la respectiva respuesta y atención por parte de los sectores oficiales, de velar por la salubridad humana y animal, así como la solidaridad y responsabilidad de las empresas, ha llevado a buscar constantemente nuevas alternativas de manejo de la mosca Stomoxys calcitrans (ICA, 2002), dentro de estas se tiene: 
1. Distribuir el raquis en lotes que necesiten mejorar las condiciones nutricionales del cultivo y las características fisicoquímicas del suelo, con el fin de incrementar o sostener niveles de producción. De acuerdo con la disponibilidad de raquis de cada plantación, se puede llevar directamente a los lotes y colocarlo sobre el suelo en cantidades que varían entre 0.25 y 1 ton/palma, dependiendo del criterio de manejo de cada plantación (CENIPALMA, 1999). El raquis se dispone de manera continua directamente en el interior de los lotes de palma distribuidos en franjas o alrededor del estípite, fundamentalmente cuando el promedio de adultos capturados, en todas las estaciones de monitoreo de los lotes, sea menor a cuarenta individuos. Cuando el promedio de adultos capturados sea superior a sesenta individuos, se procede a llevar el raquis a un área ubicada en el interior de la plantación denominada acopio (ICA, 2002).

2. Colocar trampas azules adherentes que pueden ser fabricadas de cartonplast o plástico de color azul, de un tamaño de $1 \times 0.5 \mathrm{~m}$, y es impregnada con un pegante resistente a las condiciones ambientales. Estas trampas sirven tanto para monitoreo y captura de adultos y así disminuir las poblaciones. La lectura de estas trampas, se hace en la parte inferior del tercio medio vertical en un cuadro de $0.25 \times 0.25 \mathrm{~m}$ por ambos lados de la trampa (ICA, 2002).

3. Liberar el parasitoide Spalangia sp. para el control de pupas, en proporción de 5.000 pupas parasitadas por tonelada de raquis dispuesto, es una estrategia efectiva. La liberación debe hacerse unos seis o siete días después de esparcido el raquis en el campo (ICA, 2002). Para asegurar el establecimiento del parasitoide en el campo y propiciar una mejor acción de éste, es necesario proteger las pupas parasitadas para evitar acción de los depredadores, y crear un entorno ecológico adecuado mediante la siembra de plantas nectaríferas, como la Crotalaria sp. (CENIPALMA, 1995). 


\section{ACTIVIDADES CON LOS PRODUCTORES DE PALMA}

Para determinar la fluctuación poblacional de la mosca de los establos sobre montones de raquis dispuesto en campo con diferente tiempo de cubrimiento con carpas hechas de lonas de fertilizante se realizó un ensayo en la plantación Palmas del Casanare, ubicada en la vereda la Libertad, municipio de Villanueva (Casanare), a $71^{\circ} 51^{\prime \prime}$ longitud este y $05^{\circ} 24^{\prime \prime}$ latitud norte, a una altura de 180 m.s.n.m, con una precipitación promedio de $2.400 \mathrm{~mm}$, una humedad relativa del $85 \%$ y temperatura media de $27^{\circ} \mathrm{C}$. Las evaluaciones se hicieron durante 68 días, periodo con una precipitación de $815 \mathrm{~mm}$ distribuidos en 38 días (Estación oficina de la plantación).

Para el desarrollo del experimento se seleccionaron los lotes denominados $F$ 15, $F$ 16, F 17, F 18, E 20, E 21, E 22 y E 23, teniendo en cuenta la cercanía al sitio de acopio de raquis para favorecer la presencia de mosca de los establos. La distribución de los tratamientos en los lotes se hizo en bloques completos al azar, en montones de raquis ubicados en trazo diagonal del lote a una distancia de 150 $m$ aproximadamente entre uno y otro. También se hizo liberación de Spalangia $s p$. en algunos lotes que estaban separados de los tratamientos sin liberación del parasitoide, con el fin de evitar su influencia en los resultados. La disposición del raquis se hizo en montones de $500 \mathrm{~kg}$, cubiertos con lonas, en el momento de la colocación en campo, la lona se retiró de los montones de acuerdo al tiempo establecido para cada tratamiento. En cuanto al parasitoide Spalangia sp. se liberaron cinco porciones de pupas parasitadas por montón, siendo una porción el equivalente a 5.000 pupas.

Para la cuantificación de larvas y pupas fue necesario desmenuzar el raquis, en cada montón se evaluaron tres raquis, cada ocho días después de dispuesto el raquis en campo; se tomaron muestras en el nivel inferior, medio y superior. Se cuantificaron él número de larvas y pupas por raquis, las pupas se colectaron para observar la emergencia de adultos de mosca y parasitoide en el laboratorio. 
Para el monitoreo de adultos se colocaron trampas azules adhesivas en cada montón de raquis. La lectura de las trampas se realizó en el borde inferior del tercio medio vertical en un marco de $0.25 \times 0.25 \mathrm{~m}$, en ambas caras de la trampa, dos veces por semana. Los tratamientos consistieron en cubrir los montones de raquis con carpas hechas de lonas donde se empaca fertilizante, en periodos diferentes, con y sin liberación del parasitoide Spalangia sp. siendo el testigo un montón sin cubrir (Tabla 1). Se realizó una prueba de Shapiro-Wilk para observar la normalidad de los datos y se aplicó estadística no paramétrica de Friedman de dos vías.

Tabla 1. Tratamientos para el control de la Stomoxys calcitrans

Tratamientos con Sphalangia sp.

1. Tusa con carpa durante cinco días.

2. Tusa con carpa durante diez días

3. Tusa con carpa durante quince días

4. Tusa con carpa durante veinte días

5. Tusa con carpa durante veinticinco días

6. Tusa con carpa durante treinta días

7. Tusa sin carpa

\section{Tratamientos sin Sphalangia sp.}

8. Tusa con carpa durante cinco días.

9. Tusa con carpa durante diez días

10. Tusa con carpa durante quince días

11. Tusa con carpa durante veinte días

12. Tusa con carpa durante veinticinco días

13. Tusa con carpa durante treinta días

14. Tusa sin carpa

\section{RESULTADOS Y DISCUSIÓN}

Se tomaron 10 lecturas de larvas en raquis durante 68 días, siendo las observaciones 2 y 3 en las que se registraron los valores más altos de larvas mientras la mayoría de las lecturas 1, 4, 5-10 registraron cero individuos. De acuerdo a esto se realizó una prueba de Shapiro-Wilk para observar la normalidad de los datos para los registros de larvas, donde se presentó un valor de $\mathrm{W}=0.2340$ y un $\mathrm{P}=0.0000$, es decir, que no se acepta la hipótesis de normalidad de los datos con respecto al número total de larvas.

También se hizo una transformación de los datos para corregir la normalidad mediante el factor logaritmo natural (In), sin embargo, no se corrigió la varianza aplicando la prueba de Friedman. No se encontró diferencias para los registros de 
larvas entre los bloques $\left(X^{2}=0.2813 ; g l=3 ; p=0.9635\right)$, sin embargo, entre tratamientos se encontraron diferencias $\left(X^{2}=28.950 ; g l=13 ; p=0.0067\right)$. En la Figura 1 se muestra la lectura 2, donde los tratamientos correspondientes a 30 días con carpa y con Spalangia sp., diez y treinta días con carpa sin Spalangia $s p$ (Siete días después de dispuesto el raquis) presentaron menor variación con respecto al resto de los tratamientos. Los testigos para ambos casos (con y $\sin$ liberación de Spalangia sp.) registraron los valores más altos de larvas.

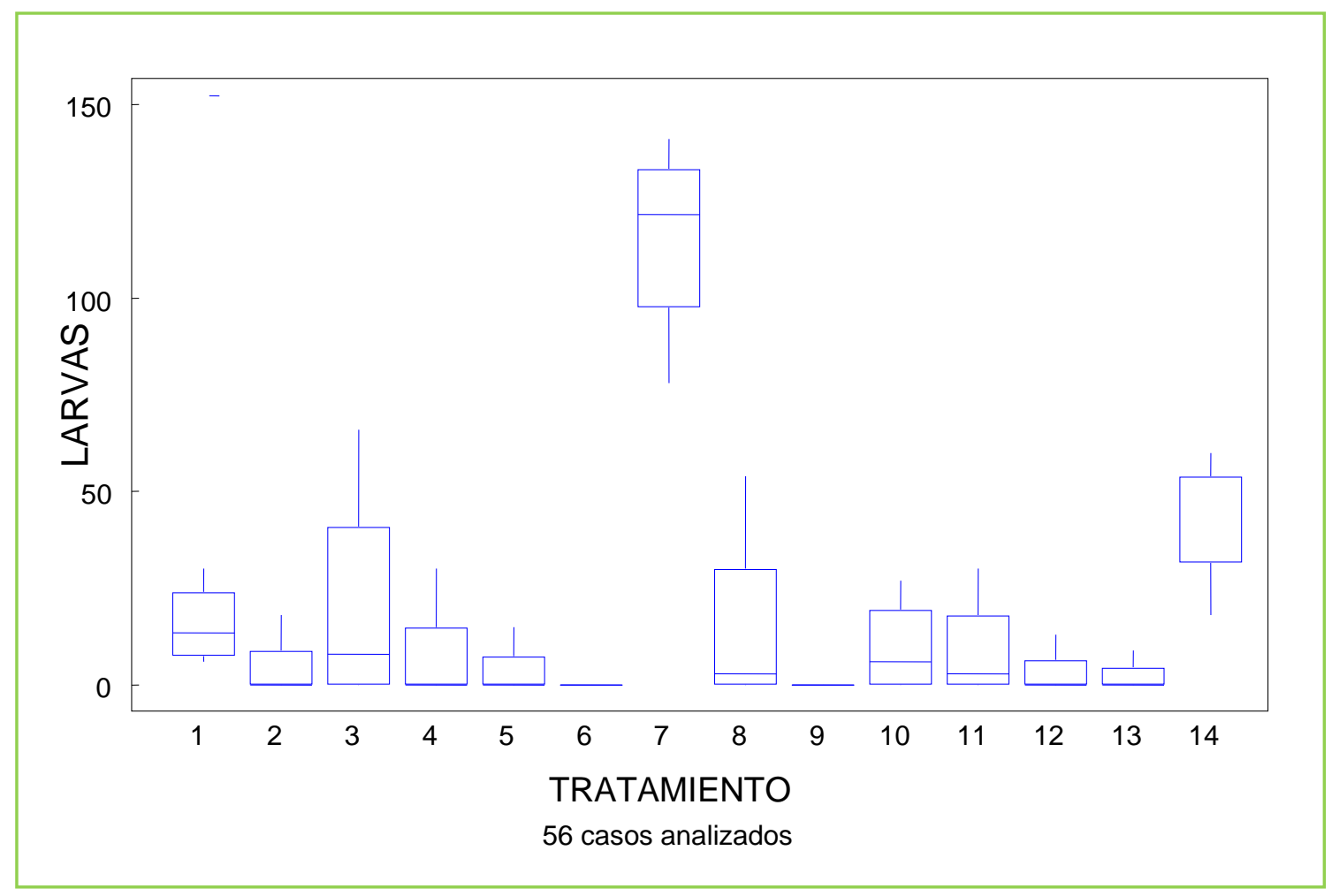

Figura 1. Promedio de larvas de mosca con y sin liberación de Spalangia

En la lectura 3 (14 días después de dispuesto el raquis) (Figura 2), se presentó menor variación en los tratamientos 15, 20 y 25 y 30 días con carpa con Spalangia $s p$. Tambien se observa el efecto del cubrimiento de las carpas sobre la población de larvas, donde los tratamientos 5 y 10 días con carpa con y sin Spalangia sp., los cuales ya se habían descubierto, registraron un número superior de larvas en comparación con los tratamientos 15,20 y 25 días y 30 días con carpa con parasitoide, los cuales no se habían descubierto hasta ese momento. 


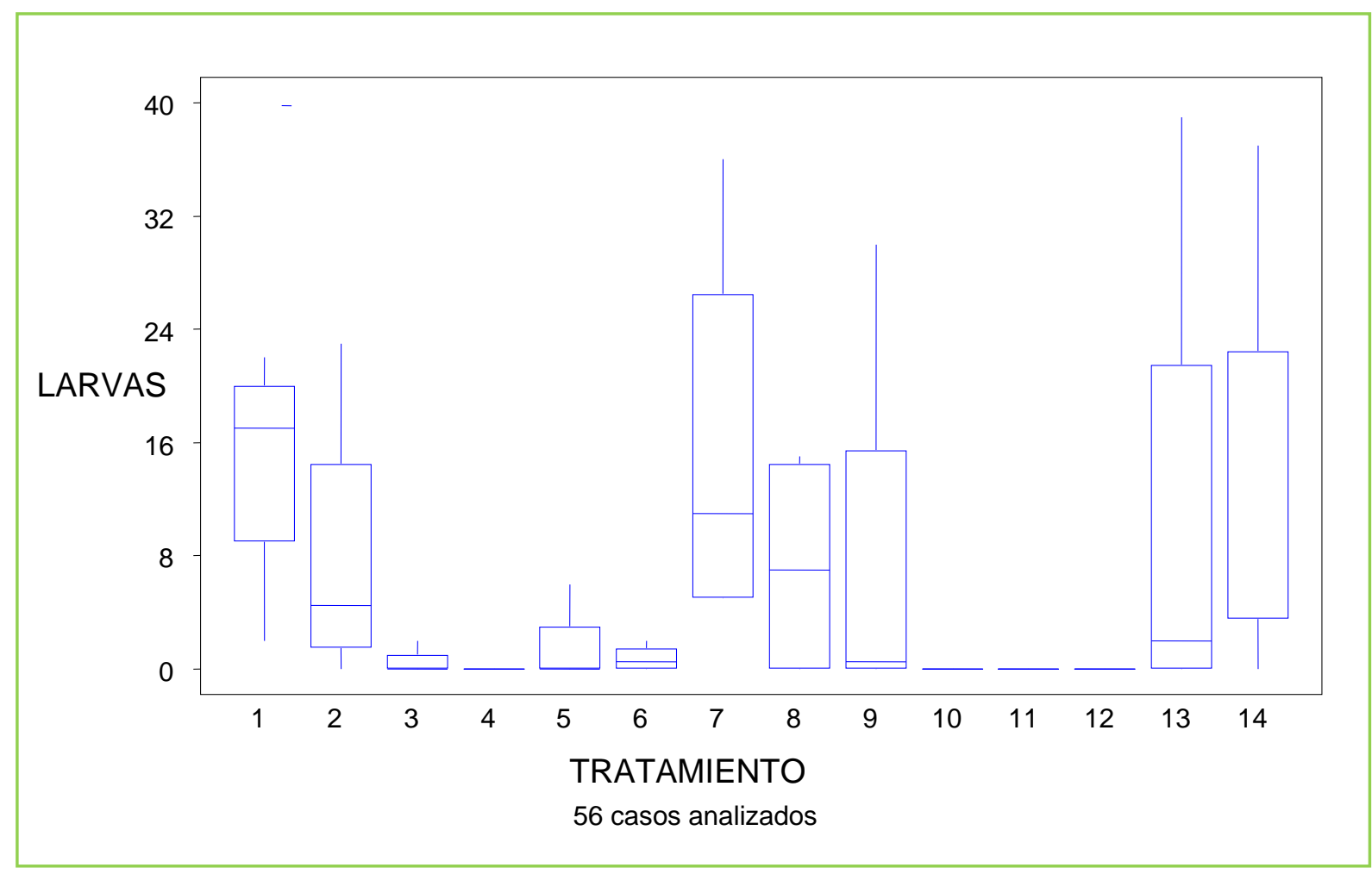

\section{Figura 2. Promedio de larvas de mosca con y sin liberación de Spalangia sp.}

Las evaluaciones de pupas registraron valores altos en lecturas, 3, 4 y 5, mientras que la mayoría de registros 1, 2, 6-10 presentaron valores de cero. Para efectos se realizó la prueba de Shapiro-Wilk, las observaciones de pupas con un valor $\mathrm{W}=0.2351$ y un $\mathrm{P}=0.0000$, es decir, no se acepta la hipótesis de normalidad de los datos con respecto al número total individuos, respectivamente. Se hizo una transformación de los datos para corregir la normalidad mediante el factor logaritmo natural (In), sin embargo, no se adaptó la varianza, entonces se aplicó la prueba de Friedman.

No se encontraron diferencias para los registros de pupas entre los bloques $\left(X^{2}=0.2813 ; g l=3 ; p=0.9635\right)$, mientras que en los tratamientos se observaron diferencias $\left(X^{2}=28.950 ; g l=13 ; p=0.0067\right)$. Esta prueba no permitió realizar una comparación de medias para identificar exactamente cuales tratamientos eran distintos. La Figura 3, muestra la lectura 3 (14 días después de dispuesto el raquis) en los tratamientos correspondientes a 15, 20, 25 y 30 días con carpa con y sin Spalangia sp. presentaron menor variación con respecto a los demás al 
realizar la comparación del testigo con y sin Spalangia $s p$. con los demás tratamientos se encontró que los testigos siempre mostraron el mayor promedio de pupas, siendo el testigo con Spalangia sp. el de valor más alto.

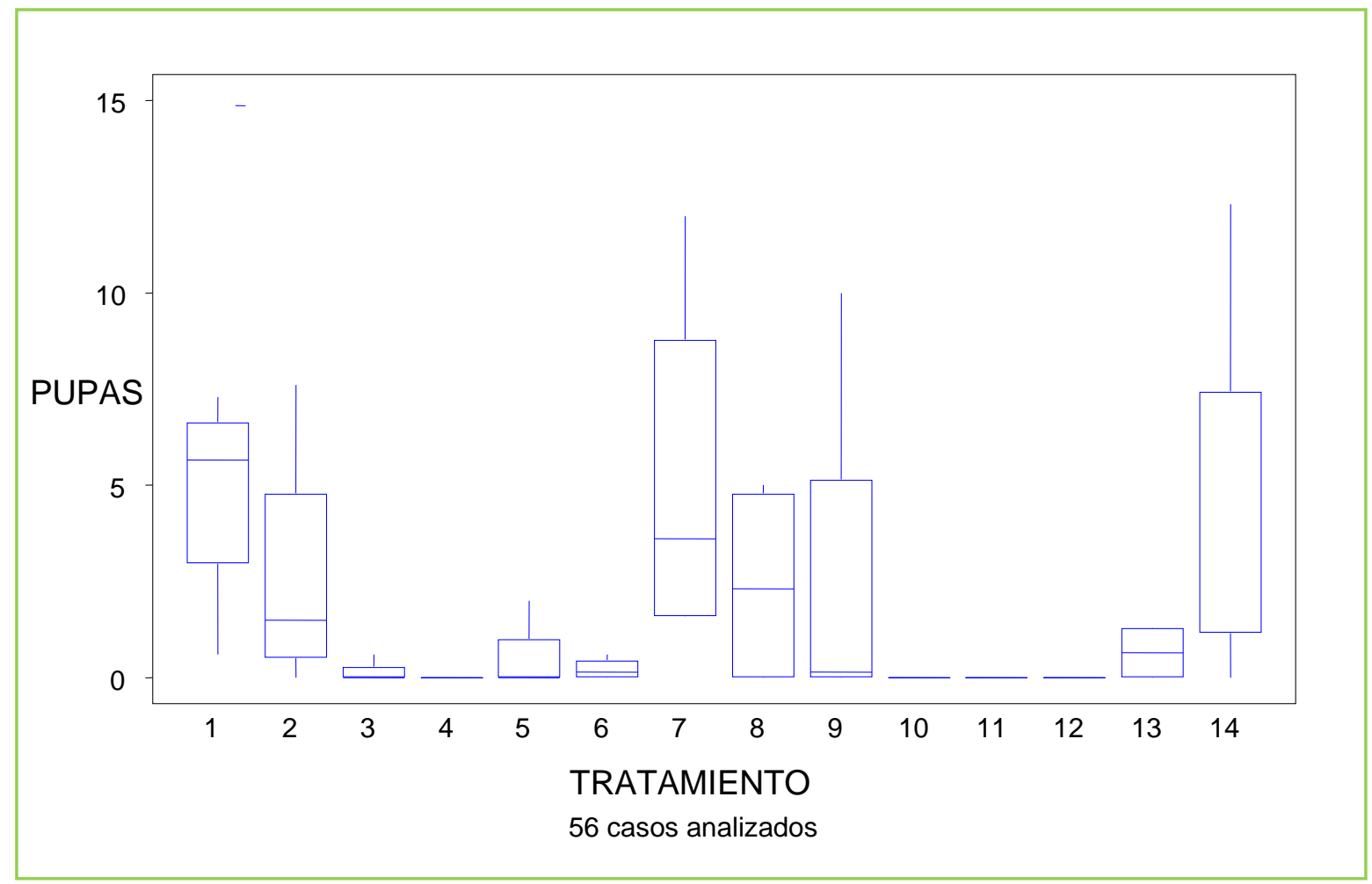

Figura 3. Promedio de pupas tratamientos con y sin liberación de Spalangia sp.

En la lectura 5, veintiocho días después dispuesto el raquis, se observó un comportamiento similar a la lectura 3 para los tratamientos 25 y 30 días con carpa con y sin Spalangia sp. Siendo los más bajos en comparación con los tratamientos con menos días de cubrimiento y los testigos; junto con el tratamiento 20 días con carpa con Spalangia sp (Figura 4).

La prueba de Shapiro-Wilk para observar la normalidad de los datos para los registros de adultos presentó un valor de $\mathrm{W}=0.6282$ y un $\mathrm{P}=0.000$, es decir, que no se acepta la hipótesis de normalidad de los datos con respecto al número total de adultos. Se hizo una transformación de los datos para corregirla mediante el factor logaritmo natural (In), sin embargo, no se ajustó la varianza, por lo tanto, se aplicó una prueba de Friedman. 


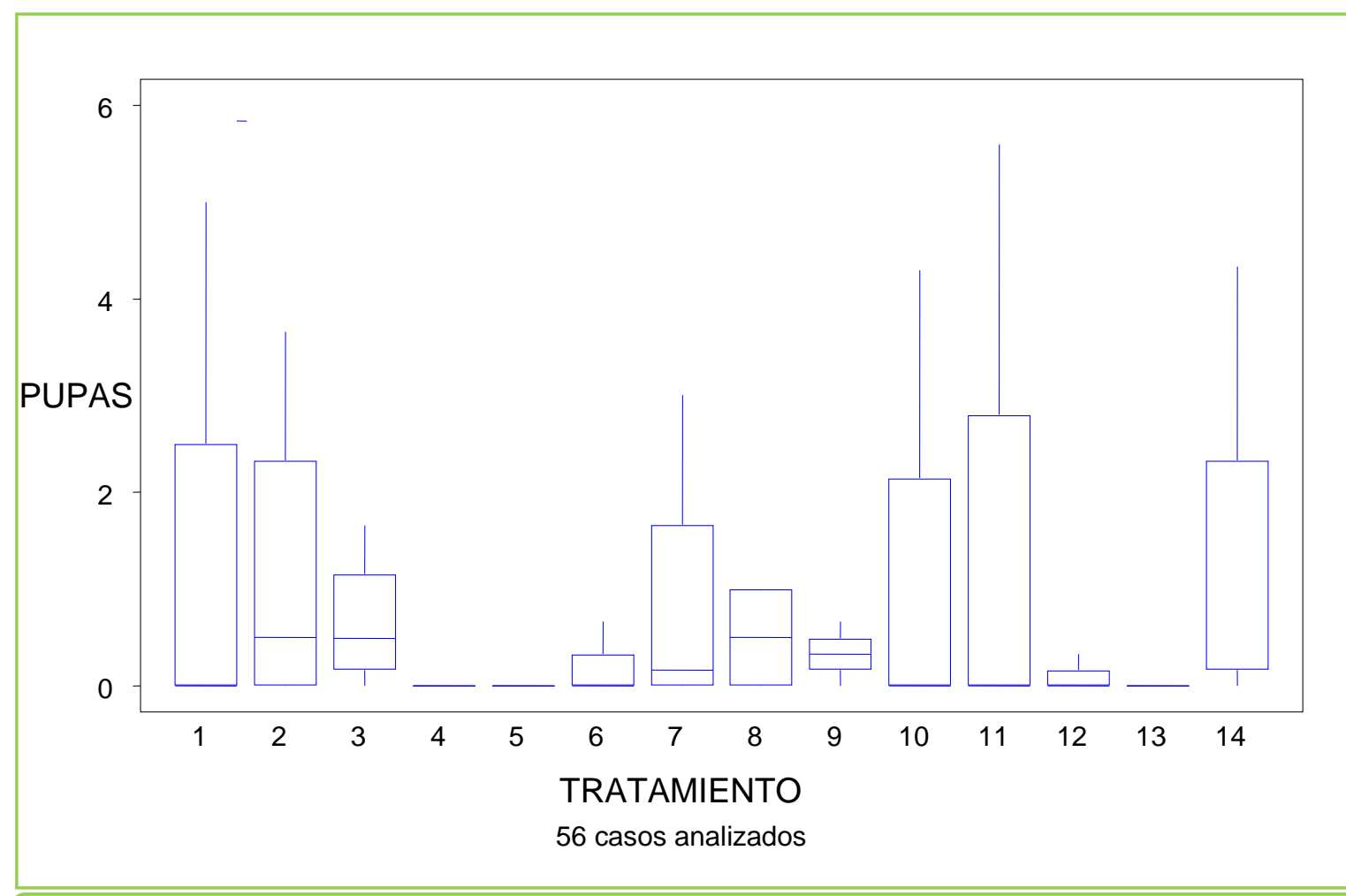

Figura 4. Promedio de pupas en montones de raquis con y sin liberación de Spalangia $s p$

En la Figura 5 se observa el comportamiento de adultos 45 días después de dispuesto el raquis, donde se registraron valores de cero para adultos en los tratamientos treinta días con carpa con y sin Spalangia $s p$ siendo los mejores en comparación con los demás tratamientos.

Para la lectura 12 (48 días después de dispuesto el raquis), los tratamientos que menos presentaron variación fueron los tratamientos 15, 20, 25 y 30 días con carpa con y sin Spalangia sp. en comparación con el resto (Figura 6). Los tratamientos que más presentaron variación, fueron 5 y 10 días con carpa con Spalangia sp. y los testigos para ambos casos.

En la evaluación de pupas se registró el mayor número de individuos (92) a los 28 días después de dispuesto el raquis, en los montones que no se les hizo liberación de Spalangia $s p$., seguido de la lectura del día 21 después de dispuesto el raquis con 55 individuos, en montones sin liberación del parasitoide. El mayor porcentaje de parasitismo de Spalangia sp. sobre pupas de mosca de los establos durante 
todo el ensayo, se dio en los montones donde hubo la liberación del parasitoide (Figuras 7 y 8 ).

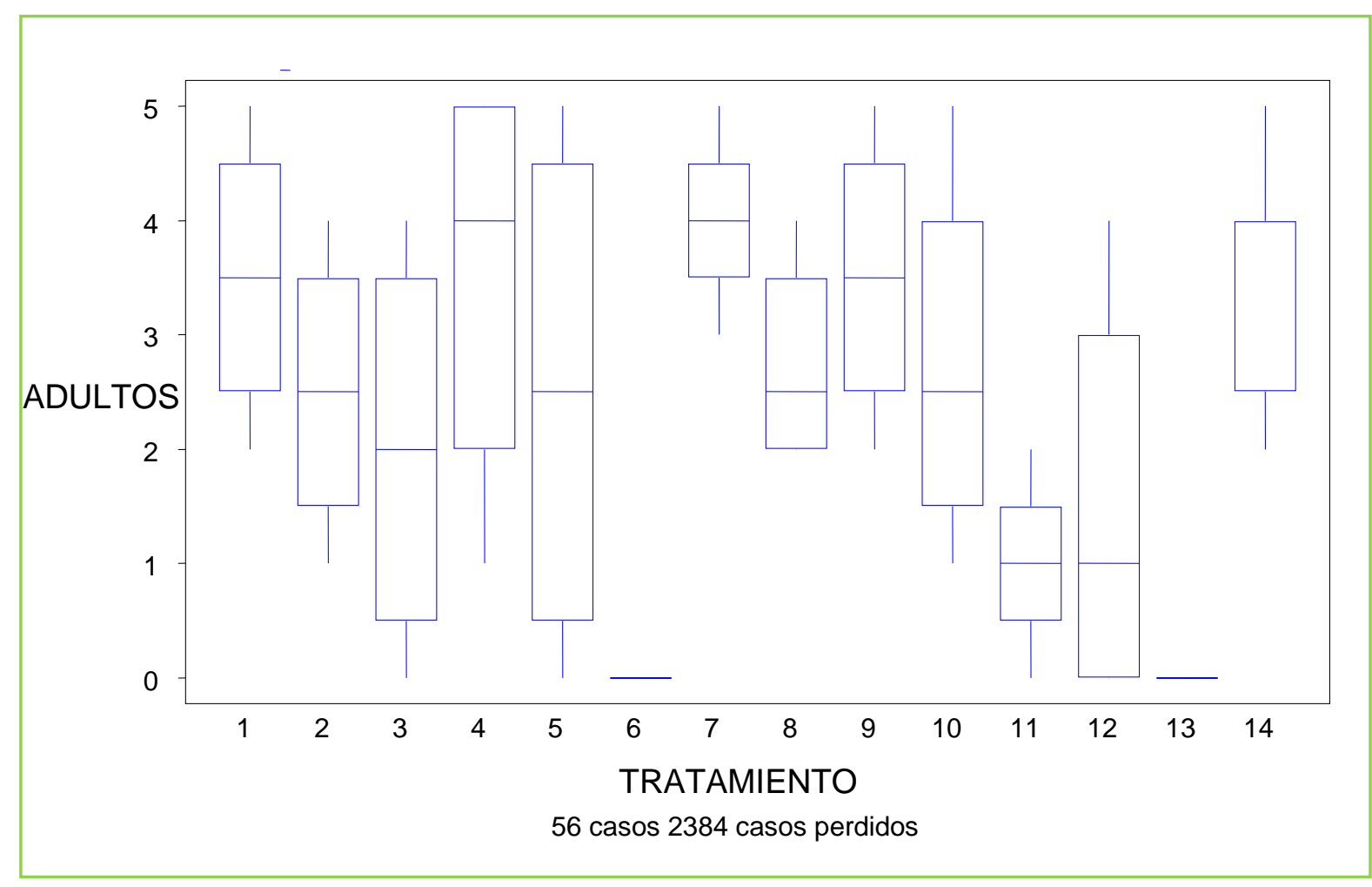

Figura 5. Numero de adultos en tratamientos con y sin liberación de Spalangia sp.

De las pupas que se colectaron y se llevaron al laboratorio se registró un porcentaje de parasitismo de Spalangia sp sobre pupas de Stomoxys calcitrans del $4 \%$ para los tratamientos que no se les hizo liberación del parasitoide y del $16.35 \%$ para los tratamientos que si se les hizo liberación. El parasitismo que se registró en los tratamientos sin Spalangia sp. se le puede atribuir a poblaciones de parasitoides ya establecidas en campo por las sucesivas liberaciones del mismo, por parte de la plantación.

También se encontró que existe un factor de mortalidad desconocido de pupas de mosca en campo, y que correspondió al $44.2 \%$ y $39 \%$ en los tratamientos sin y con liberación de Spalangia spp respectivamente, durante todo el periodo que duró el experimento. Además, se registró una diferencia del $7.1 \%$ en cuanto a la emergencia de adultos de mosca, entre los tratamientos con y sin liberación de 
Spalangia $s p$, siendo menor en los tratamientos que se les hizo liberación del parasitoide, posiblemente por el efecto del parasitoide sobre el desarrollo biológico de las pupas de mosca.

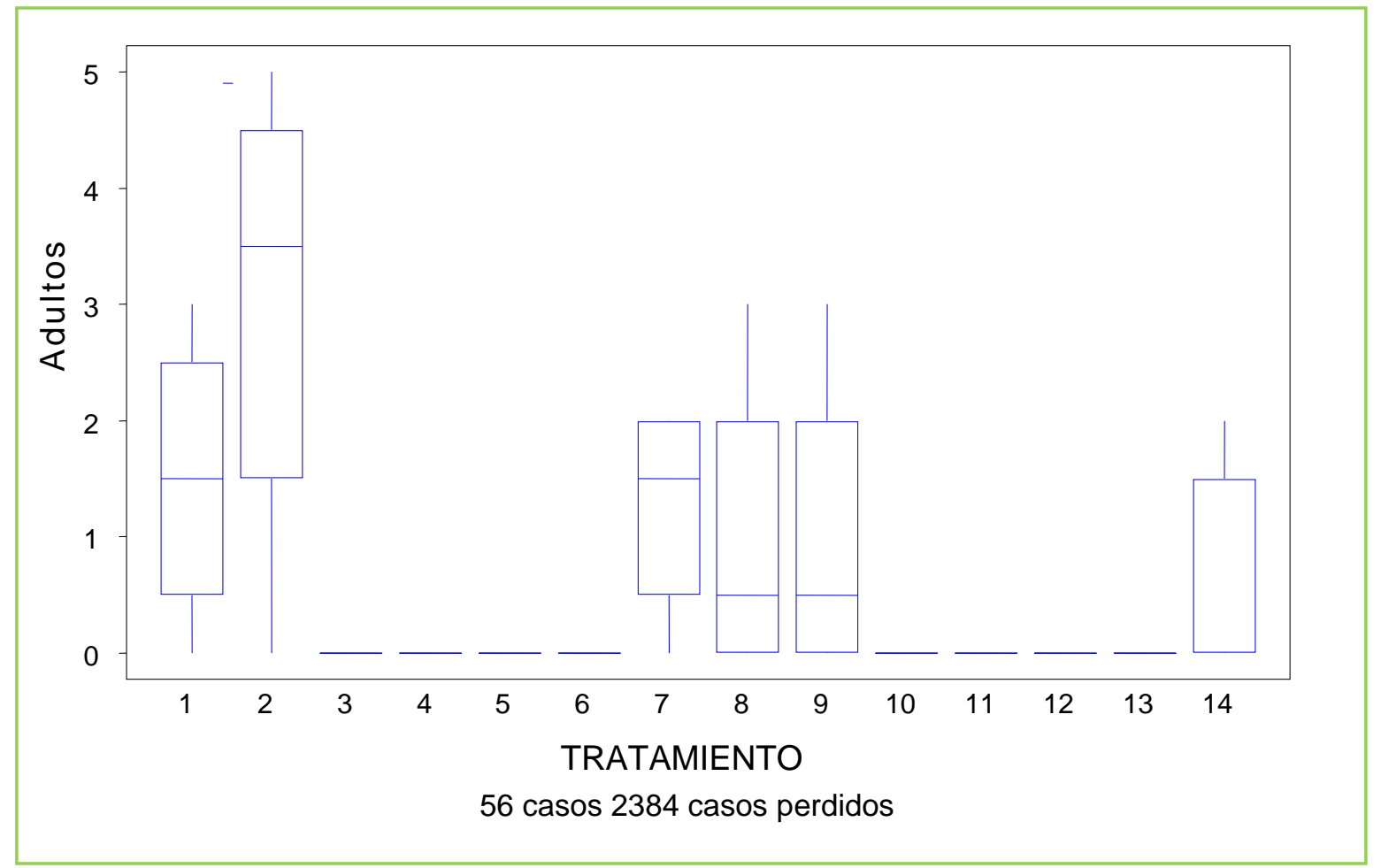

Figura 6. Número de adultos en montones de raquis con y sin Spalangia sp.

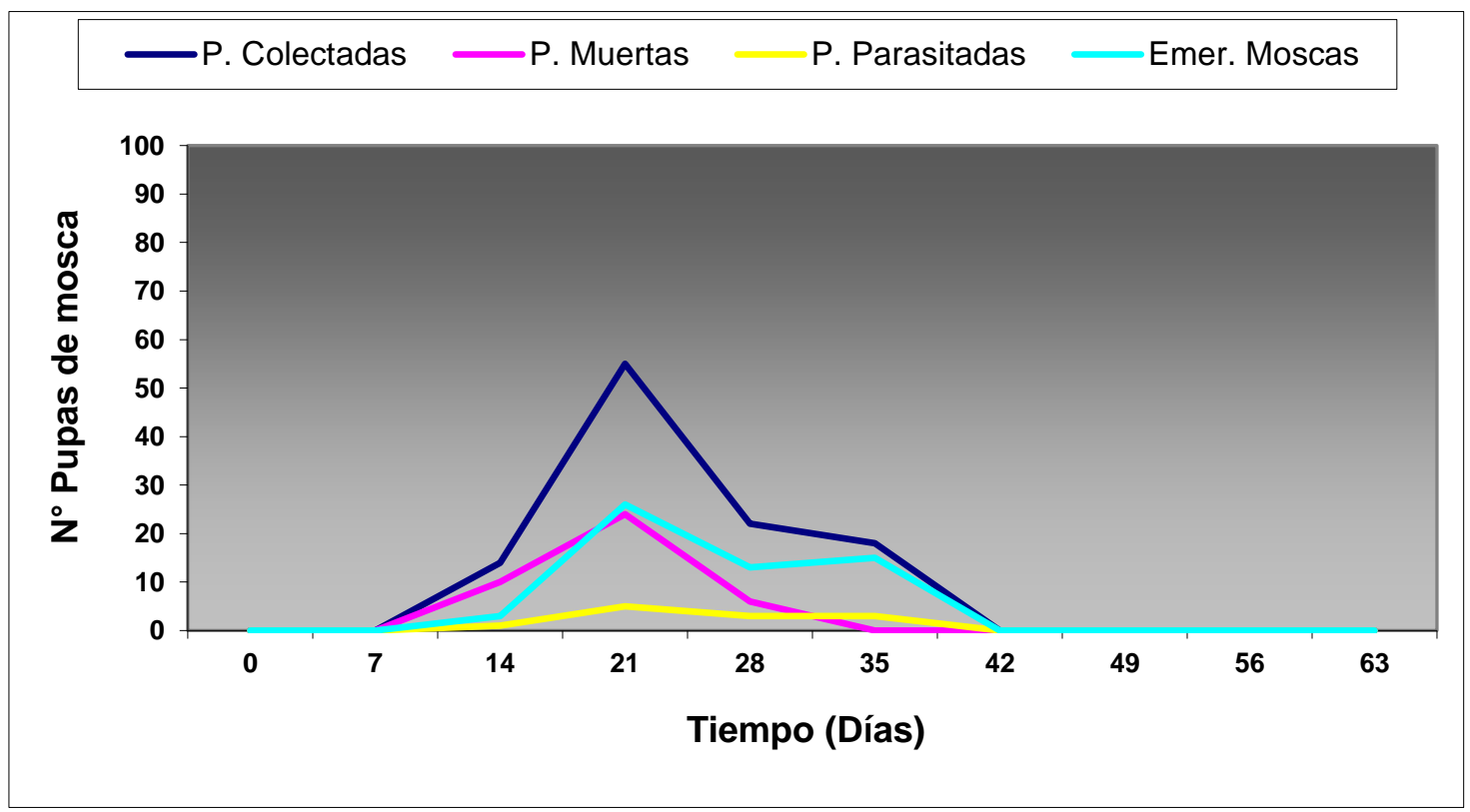

Figura 7. Evaluación del parasitismo de Spalangia sp sobre pupas de Stomoxys calcitrans en tratamientos con liberación del parasitoide. 


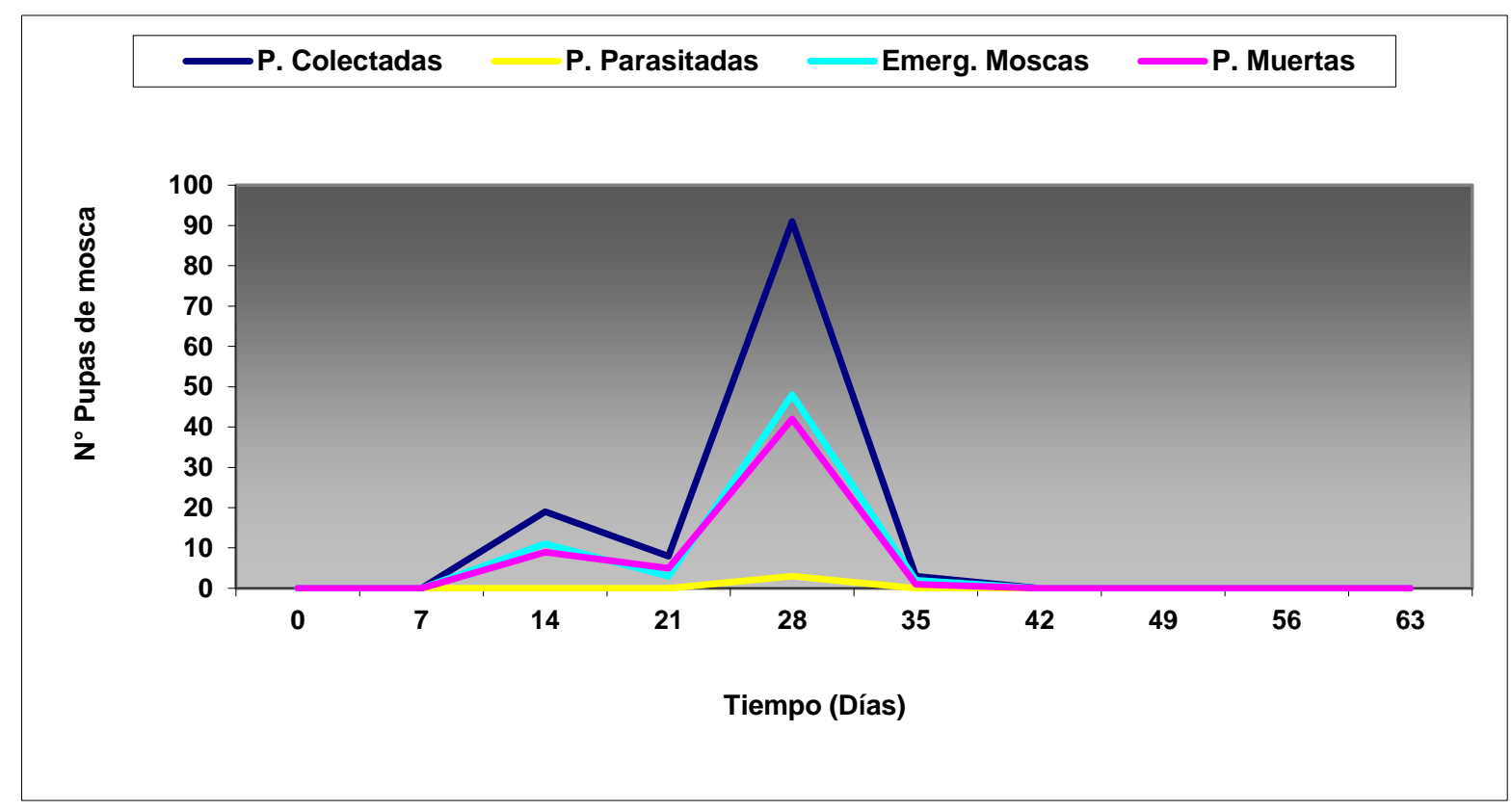

Figura 8. Evaluación del parasitismo de Spalangia sp sobre pupas sin liberación del parasitoide.

\section{CONCLUSIONES Y RECOMENDACIONES}

Si se observó un efecto del cubrimiento del raquis con carpas hechas de lonas, sobre la población de mosca. Los tratamientos 20, 25 y 30 días con carpa con y sin Spalangia sp. fueron los que presentaron un mayor desarrollo biológico de la mosca de los establos. El parasitismo de Spalangia sp sobre pupas de mosca de los establos, disminuyó en $16.35 \%$ la población, lo cual demuestra la importancia de las liberaciones de este parasitoide, ratificando la necesidad de mantener poblaciones establecidas en campo, para un eventual manejo de raquis con carpas, como un componente de dentro de la técnica del cubrimiento. También se observó que existe un factor de mortalidad natural de $41 \%$ de mosca de los establos en estado de pupa en campo.

Se recomienda utilizar carpas hechas de lona (doble) de material sintético, evitando perforaciones que faciliten el paso de moscas de los establos. Hacer montones de raquis de $500 \mathrm{~kg}$, utilizando carpas de 20 lonas cocidas a lo ancho en 5 hileras. Colocar trampas azules adhesivas en los lotes en donde se distribuya 
raquis cubierto con carpas. Cubrir en el menor tiempo posible el raquis en campo para evitar la oportunidad de que la mosca de oviposite antes de cubrir los montones de raquis. Evaluar periódicamente y al azar raquis cubiertos con carpas para verificar la ausencia de estados inmaduros de mosca. Adelantar más investigaciones sobre el manejo de raquis en campo tendientes a disminuir la posibilidad de desarrollo de la mosca de los establos.

\section{REFERENCIAS BIBLIOGRÁFICAS}

1. Bernal F. El cultivo de la palma de aceite y su beneficio. Bogotá. 2001.

2. Campbell J. Stable fly control on cattle. Nebguid. g. 93-1152. 1993.

3. Cumming J., Cooper, B. Artrópodos associated with livestock dung stable fly Stomoxys calcitrans (L.) animal protection systemactics. apss home page. Livestock dung arthropods. Filth fly pests. Index. Agriculture \& Agriffood Canada. 2000.

4. CENIPALMA. Manejo integrado de plagas. Ceniavances 7. Bogotá. 1995.

5. CENIPALMA. Manejo integrado de plagas en palma de aceite. Curso Nacional. Bogotá. 2002.

6. CENIPALMA. Manejo integrado de la mosca de los establos Stomoxys calcitrans. Ceniavances, 57. Bogotá.1999.

7. CENIPALMA. Plagas de la palma de aceite en Colombia. $2^{\mathfrak{a}}$ ed. Bogotá. 2003.

8. CENIPALMA, CORPOICA, ICA. Manejo de la mosca de los establos. Bogotá. 1995.

9. Diaz L. Estudios básicos para un manejo integrado de la mosca de los establos Stomoxys calcitrans (diptera:muscidae). tesis de grado. UNALI.1995.

10. Diaz L.; Luque J.; Calvache H.; Hernandez M. Estudios básicos para el manejo integrado de la mosca de los establos Stomoxys calcitrans (L.). Palmas (Colombia) 18 (3): 19 - 29.1997.

11. Georgi R. Parasitología para veterinarios. $4^{a}$ Ed. New York: W.B. Saunders Company, 1985.

12. ICA. Plan de manejo de la mosca de los establos Stomoxys calcitrans. Boletín técnico. Villavicencio. 2002.

13. León H. Villanueva capital agroindustrial, turística y cultural del departamento de Casanare. Informe de gestión. 2003.

14. Morgan D.; Bailie, H. A fiel trial to determine the effect of fly control using permethrin on milk yields in dairy cattle in the $u$. k. veterinary record: 106: 121123.1980 .

15. Okedi L. Least specific sucker of vertebrate blood. in insect records. Chapter 10. University of Florida. Gainesville. USA. 1995.

16. Powell P. Stable fly biology and management. West Virginia University. Extension service. 3 p.1995.

17. Reyes A; Duran, C.; Cruz, M. Efecto de la aplicación de materia orgánica a base de raquis de racimos en palma de aceite. Artículo técnico 6. Conferencia Internacional "Avances Agronómicos de Palma de Aceite" Cartagena.1997 
18. Roberts R.; Pund, W. Control of biting flies on beef steers: effect on performance in pasture and feed Lot. J. Econ. Entomol. 67: 232-234.1974.

19. Serrano C. Control de moscas y su importancia económica. Boletín Científico. Santa Fe de Bogotá. D.C. 1996. 